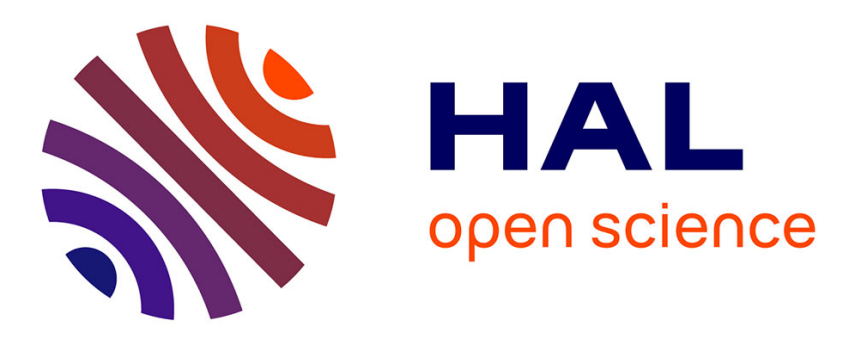

\title{
Product Change in a Small Company: Effects on Eco-price and Global Productivity
}

Nilson Carvalho, Biagio Fernando Giannetti, Feni Agostinho, Cecilia De Almeida

\section{- To cite this version:}

Nilson Carvalho, Biagio Fernando Giannetti, Feni Agostinho, Cecilia De Almeida. Product Change in a Small Company: Effects on Eco-price and Global Productivity. IFIP International Conference on Advances in Production Management Systems (APMS), Sep 2014, Ajaccio, France. pp.178-186, 10.1007/978-3-662-44736-9_22. hal-01387864

\section{HAL Id: hal-01387864 \\ https://hal.inria.fr/hal-01387864}

Submitted on 26 Oct 2016

HAL is a multi-disciplinary open access archive for the deposit and dissemination of scientific research documents, whether they are published or not. The documents may come from teaching and research institutions in France or abroad, or from public or private research centers.
L'archive ouverte pluridisciplinaire HAL, est destinée au dépôt et à la diffusion de documents scientifiques de niveau recherche, publiés ou non, émanant des établissements d'enseignement et de recherche français ou étrangers, des laboratoires publics ou privés.

\section{(c)(1)}

Distributed under a Creative Commons Attribution| 4.0 International License 


\title{
Product change in a small company: effects on eco-price and global productivity
}

\author{
N. Carvalho, B. F. Giannetti, F. Agostinho and C. M.V.B. Almeida (*) \\ Programa de Pós -Graduação em Engenharia de Produção da Universidade Paulista \\ Rua Dr Bacelar 1212, Mirandópolis, 04026-002 - São Paulo, Brazil. (*) cmvbag@ unip.br
}

\begin{abstract}
The notion of supply chain thinking working to reduce the environmental and socioeconomic burden associated with a manufactured product or selection of products throughout their value chain was recently recognized. However, there are also several types of small businesses that arise in the sphere of influence of large supply chains in order to fill gaps or serve customers with special needs, which have not been considered or assessed. These small companies, in general, have little or none influence on decisions made along the entire supply chain, and have to adapt their production processes induced by decisions made by the leading companies within the chain. This work assesses the changes in the environmental resource use of a small company operating in the Brazilian automotive aftermarket using emergy synthesis and confirms the idea that the supply chain thinking works to reduce the environmental reducing the burden associated with products manufacturing within the value chain. The simulation performed for the period 2014-2025, within the company's business plan, shows that the sooner the exchange of products is made, the greater the profits of the company with regard to eco-efficiency and environmental responsibility.
\end{abstract}

Keywords: emergy; automotive aftermarket; resource use, eco-price

\section{Introduction}

Manufacturing activities are among the largest contributors for mankind's usage of resources. With the expansion in economic activities, environmental concerns are gaining increasing awareness and environmental actions are developing to preventive approaches. Recently, the adoption of more holistic strategies by authorities and companies, in which all energy and resource use throughout the products' value chain are examined, has been recognized. Thus, the notion of supply chain thinking works to reduce the environmental and socioeconomic burden associated with a manufactured product or selection of products throughout their value chain.

In this context, there are also several types of small businesses that arise in the sphere of influence of large supply chains in order to fill gaps or serve customers with special needs. These small companies, in general, have little or none influence on decisions made. Decisions made by the leading companies within the chain end up causing effects, which may or may not be positive, both with regard to the revenue of these small businesses, as the environmental impact they may cause individually.

To provide evaluation external to the economy, and at the same time, adherent to the fundamental laws of thermodynamics, an environmental accounting method for energy invested in environmental and human systems, called emergy synthesis, was developed by [1]. This method of valuation recognizes the relationships between nature's production of raw materials and their consumption by mankind to be quantified in an equivalent physical unit, which can be then translated into monetary terms.

Emergy synthesis has been successfully used to evaluate manufacture processes. [2] analyzed the resource utilization and environmental performance of a multi-product system, which was divided into two categories: inseparable multi-product systems and semi-independent multi-product systems. These authors concluded that if the product belongs to an inseparable multiproduct system, its emergy equals that for the entire system, but if it belongs to a semi-independent multi-product system, inputs must be shared. Announcing a new method, based upon emergy synthesis, [3] highlight the internal relations among the different subsystems and components. The emergy-based method provides insight into the environmental performance and sustainability of an industrial park. Results from Dalian Economic Development Zone case show the potential of emergy synthesis method at the industrial park level for environmental policy making. Emergy advantages and limitations are discussed for future research. The 
impact of waste emissions on the environment was evaluated by [4], who propose an amplification factor to improved emergy indicator. To illustrate the usefulness and highlight their superiority over standard indices, the improved emergy indicators were used to evaluate the interaction between a commercial polyethylene production process incorporating waste management and its surrounding environment.

In a more comprehensive study, [5] reports the experiences of a medium size gold-plated jewelry company, located in São Paulo, Brazil, in order to reduce waste and pollution. Actions taken, the changes that have been introduced, their cost-effectiveness and the additional benefits accomplished were presented. The results of a waste minimization program and of a Cleaner Production intervention were complemented with the use of global scale performance indicators (Material intensity, MIs, and Emergy accounting), which have shown that little changes within the company reduce upstream impacts and that benefits to the environment are greater than that observed in the company's neighborhood. Human health and environmental concerns were considered at in evaluating the options to reduce or eliminate lead from the manufacturing environment is its replacement with

lead-free alloys [6]. Applying emergy synthesis and the DALY indicator (Disability Adjusted Life Years) to assess the impact of manufacturing soft solder showed that more resources are used to produce one ton of lead-free solders than to produce one ton of tin-lead solders, with and without the use of consumer waste recovered through a reverse logistics system. The assessment of air emissions during solder production shows that the benefits of the lead-free solution are limited to the stages of manufacturing and assembling. The tin-lead solder was pointed as the best option in terms of resource use efficiency and with respect to emissions into the atmosphere when the entire supply chain is considered.

The goal of the company is to consolidate its presence in the automotive supply chain in the coming years, totally substituting the production of carburetor gaskets for electronic injection ones till 2025 . The objective of this work is to assess and foresee the changes in the environmental resource use of a small company operating in the Brazilian automotive aftermarket during the process of product change induced by the main supply chain.

\section{Company description}

JP JOINTS started its activities for the automotive aftermarket in 1992, with a distribution chain that requires a spread of products and services from suppliers. The company specialty is automotive sealing products, which involve more than 1,500 items this market. The company, which started its activities by providing spare gaskets for carburetor engines, had to adapt to the new demand for gaskets for engines with electronic fuel injection. Today, the leading products of the company are carburetor and electronic injection gaskets, with a production of more than a million units per year.

Figure 1 shows the leading gasket models used for replacement in old engines and the substitute for vehicles with electronic injection.

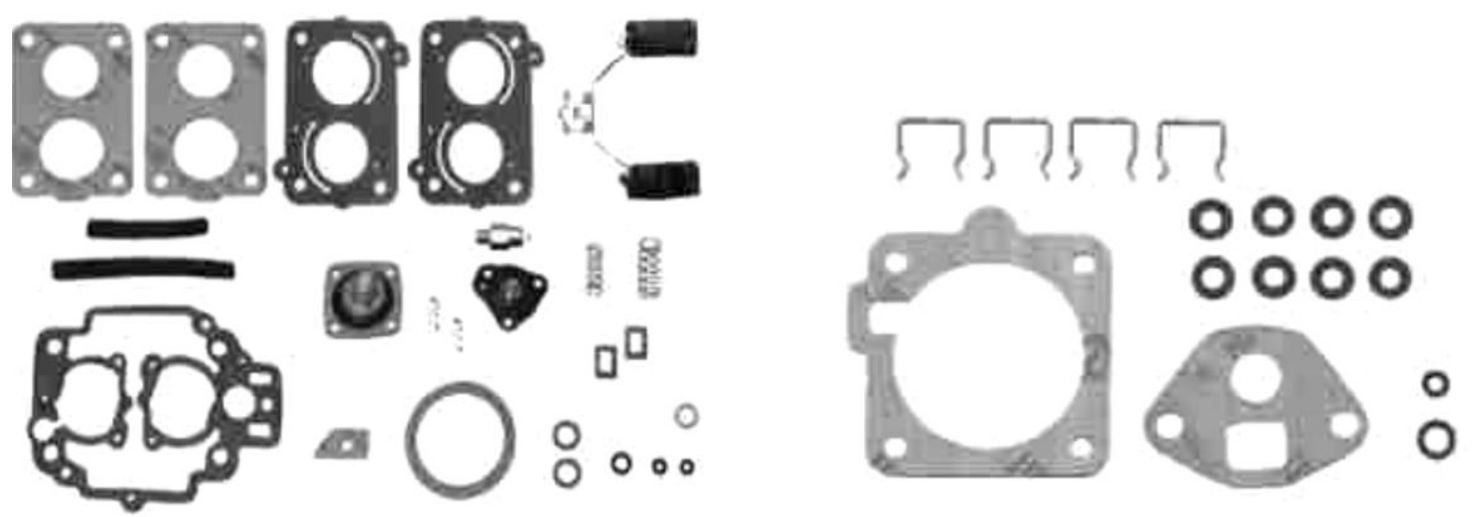

Figure 1. Carburetor (left) and electronic injection (right) kits produced by the company.

\section{Methods}

Emergy is defined as the available energy previously required, directly and indirectly, through input pathways to make a product or service [1]. The emergy evaluation was performed for the conversion of all contributions received by the production system (metals, energy, oil, and currency) on a single base of measurement (sej). The effect of the product change can thus be compared regarding efficiency in resource use, productivity, environmental burden and global productivity. The evaluation procedure for 
the system was performed by means of data collection through on the formal documents of purchase, in the year 2013, accordingly to the following steps: (i) study of the context in which the system is inserted; (ii) definition of the system under study including its limits for investigation and description of manufacturing processes; (iii) execution of the mass balance and construction of energy flows diagram; (iv) construction of the emergy tables with data collected; and (v) discussion for future management actions. For each type of gasket, the quantities of electricity consumed, water, paper and cardboard, lubricating oil, labor, were calculated. The quantities of materials used in the implantation of the system were accounted for by considering its useful life. Unit Emergy Values (UEVs) used in this text are mostly taken from the literature, and are relative to the $15.83 \times 10^{24} \mathrm{seJ} /$ year baseline [7].

The Emprice [1] or eco-price [8] have the purpose of more precisely representing the value of environmental resources than the alternative approach of "willingness to pay". The Emprice is the quotient of emergy to dollars of the area where the system is inserted. The emergy to dollar ratio of the State of São Paulo is $1.7 \times 10^{12} \mathrm{sej} / \mathrm{US}$ [7]. The Emergy to dollar ratio of the company is also calculated, by the quotient between the total emergy and the company's revenues. The Global Productivity (GP) was calculated similarly to common productivity, which is the ratio of inputs and outputs. Estimated in emergy terms, through the ratio energy to emergy, GP considers resources, energy and services of the biosphere embedded into the UEVs, and consequently is broader than productivity usually calculated.

\section{Results}

Figure 2 shows the energy diagram of the company.

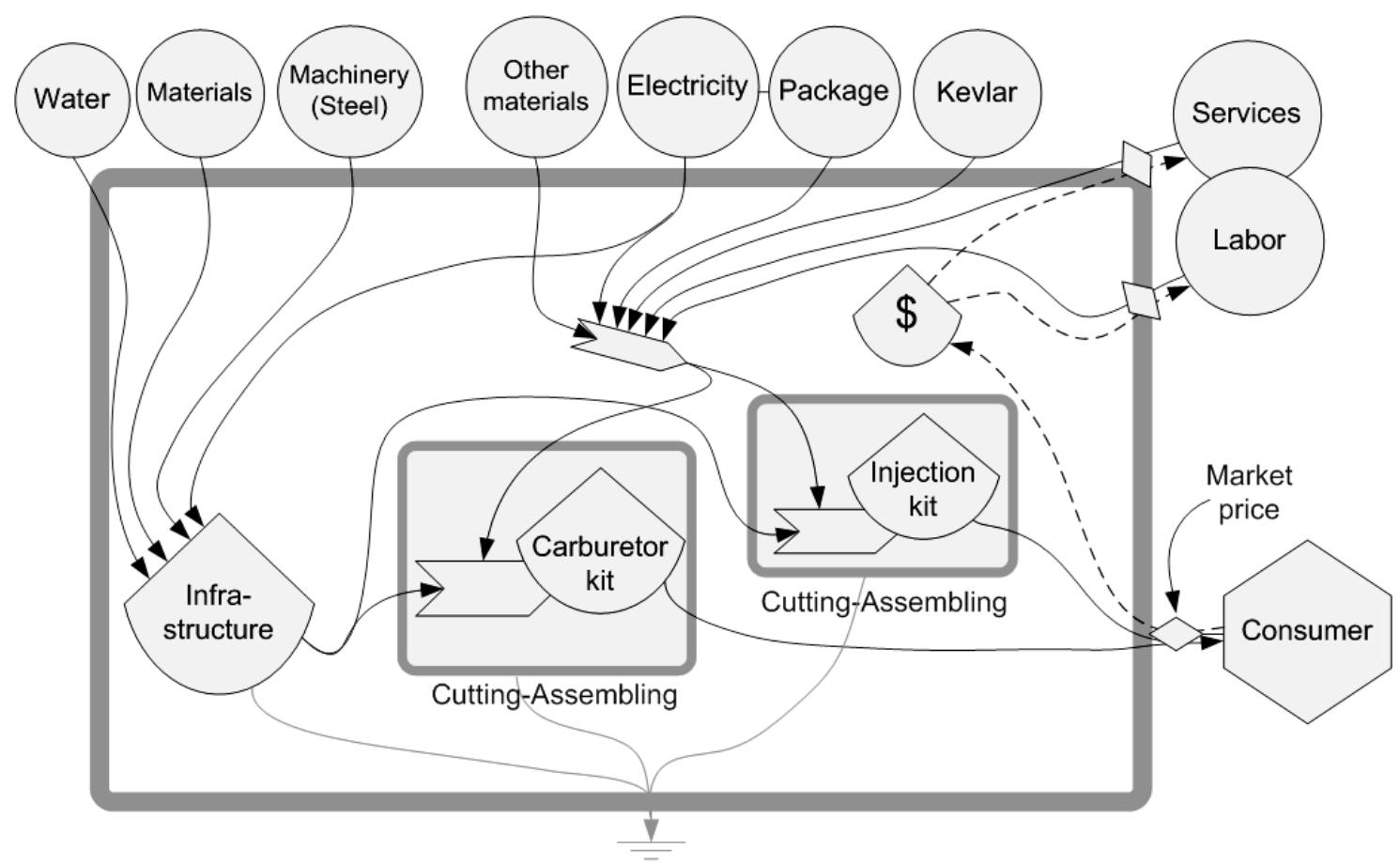

Figure 2. Energy system diagram of JP juntas.

Table 1 shows the emergy environmental accounting of the company in 2013. This year, equal amounts of both types of joints were produced. However, the emergy spent in the production of carburetor kits was two times greater that used to produce the same amount of electronic injection ones. The emergy costs of the firm, represented by the annual cost of facility building, offices and machinery, account for only $7 \%$ of the total annual cost.

The production of the carburetor kit (67,4\% of the total emergy) and, as expected, the major contribution for the total emergy comes from the Kevlar gaskets, followed by the cellulose ones. 
Table 1. Emergy environmental accounting of JP Juntas in 2013.

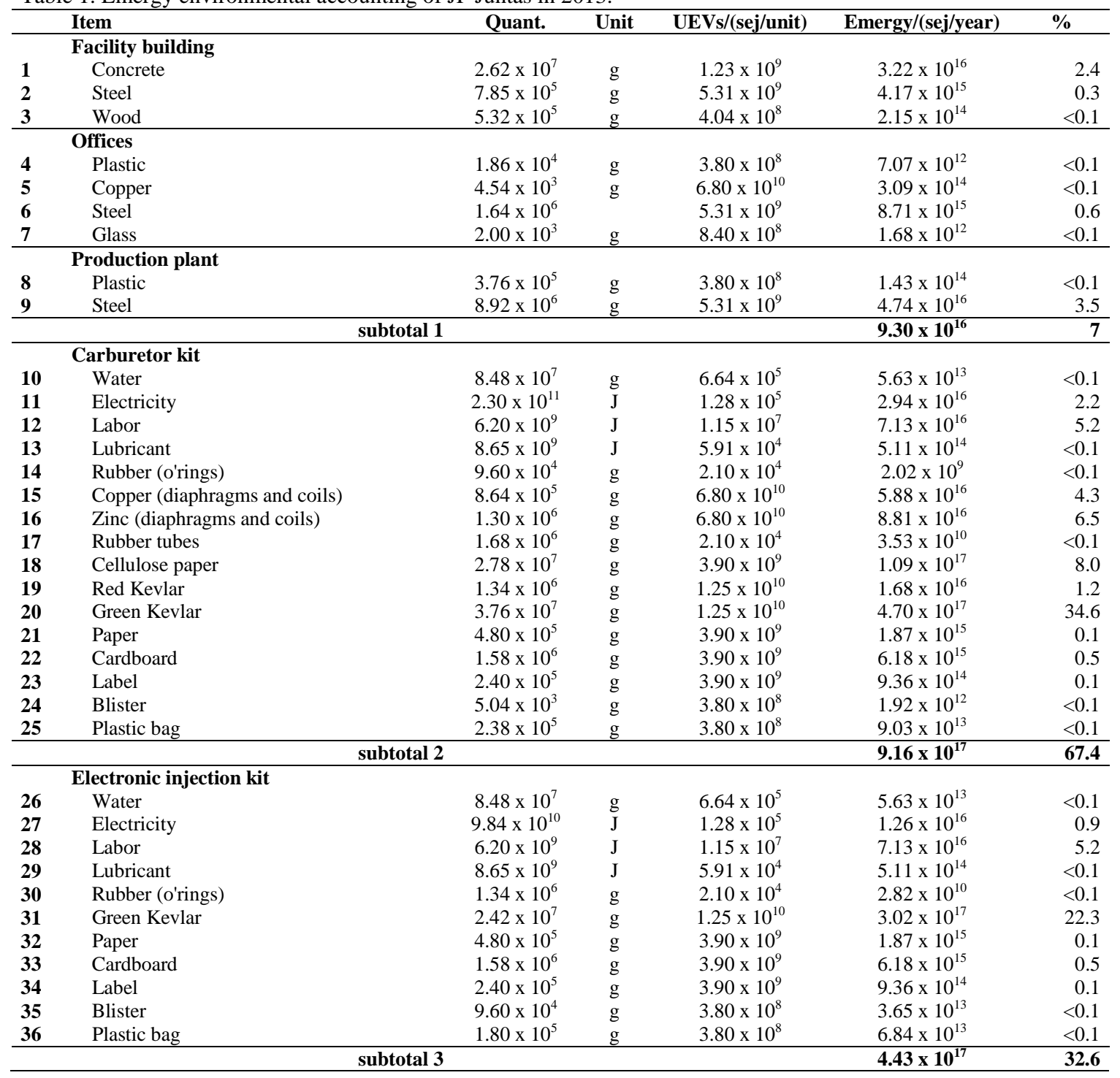

The total emergy of the company in 2013 accounts for all the resources and energy required to produce 480,000 kits of gaskets for carburetor and electronic injection engines (Tab. 2).

The UEVs, which translate the use of energy and resources in emergy terms per energy unit of product, shows that it takes approximately the double of emergy to produce one carburetor kit. This is unfavorable both to the environment and the company as the carburetor kit is sold by U $\$ 2.00$ while the electronic injection kit by U\$3.50. The kits' EMR also show that less emergy is used to produce electronic injection kits per unit of final product.

Table 2. Summary of emergy environmental accounting of JP Juntas in 2013.

\begin{tabular}{lccc}
\hline & Carburetor & Electronic injection & Total \\
\hline Total emergy 2013 (sej/year) & $9.63 \times 10^{17}$ & $4.89 \times 10^{17}$ & $1.45 \times 10^{18}$ \\
UEV (sej/kit) & $4.01 \times 10^{12}$ & $2.04 \times 10^{12}$ & $2.83 \times 10^{12}$ \\
& & & 799,235 \\
Emprice* (Em\$/year) & 566,198 & 287,797 & $1.10 \times 10^{12}$ \\
EMR** (sej/U\$) & $2.01 \times 10^{12}$ & $5.82 \times 10^{11}$ & $1,320,000$ \\
Revenues (U\$/year) & 480,000 & 840,000 & \\
\hline
\end{tabular}

*The Emprice is the quotient of emergy to dollars $\left(1.7 \times 10^{12} \mathrm{sej} / \mathrm{U} \$\right.$, [7] of the area where the system is inserted. **The emergy to dollar ratio of the company is also calculated, by the quotient between the total emergy and the company's revenues.

Since the company's plans are to reduce gradually the production of carburetor kits with the end in 2025 , a predictive accounting was performed to assess the impact of this managerial decision in the environmental accounting of the company in the next years. The simulation took into account some factors, which were foreseen: 
- the reduction in the number of carburetor kits would be compensated with the production of electronic injection ones;

- the reduction of electricity use, due to the reduced number of cutting operations, was calculated and accounted in proportion to the number and kind of kits produced;

- the reduction of labor force, in 2020, was estimated in proportion to the number and kind of kits produced;

- $\quad$ the price of the kits was maintained constant.

Table 3 shows the results of the environmental accounting of the company till 2025. It is clear that as the percentage of electronic injection kits increase, the total emergy of the company decreases along with the use of energy and materials to produce one unit of product (UEVs). The Emprice, which translates the emergy costs into currency values, also decreases by $35 \%$, while the company`s revenues increase by $24 \%$.

Table 2. Summary of emergy environmental accounting of JP Juntas in the period of 2014 to 2025.

\begin{tabular}{|c|c|c|c|c|c|c|c|c|c|c|c|c|}
\hline & 2014 & 2015 & 2016 & 2017 & 2018 & 2019 & 2020 & 2021 & 2022 & 2023 & 2024 & 2025 \\
\hline \% Electronic injection gasket emergy & 37 & 41 & 45 & 50 & 54 & 60 & 64 & 70 & 77 & 84 & 92 & 100 \\
\hline Total emergy x $10^{18}$ (sej/year) & 1.32 & 1.28 & 1.24 & 1.20 & 1.16 & 1.12 & 1.05 & 1.01 & 0.97 & 0.93 & 0.89 & 0.85 \\
\hline UEV x $10^{12}$ (sej/kit) & 2.74 & 2.66 & 2.58 & 2.50 & 2.42 & 2.34 & 2.19 & 2.11 & 2.02 & 1.94 & 1.86 & 1.77 \\
\hline EmPrice x $10^{6}(\mathrm{Em} \$ /$ year $)$ & 0.8 & 0.8 & 0.7 & 0.7 & 0.7 & 0.7 & 0.6 & 0.6 & 0.6 & 0.5 & 0.5 & 0.5 \\
\hline Revenues x $10^{6}$ (U\$/year) & 1.35 & 1.38 & 1.41 & 1.44 & 1.47 & 1.5 & 1.53 & 1.56 & 1.59 & 1.62 & 1.65 & 1.68 \\
\hline
\end{tabular}

It is also remarkable that the change of products, despite induced by the larger firms in the supply chain, may bring additional benefits to JP JUNTAS. Figure 2 shows that the emergy embedded into products might decrease by $31 \%$ in 2025 . This emergy savings will be available to other uses within the biosphere. A decrease of $17 \%$ in the emergy costs for maintenance, use of auxiliary materials and labor is foreseen, and the use of packaging materials is expected to significantly diminish by more than $80 \%$, while the company's revenues increase.

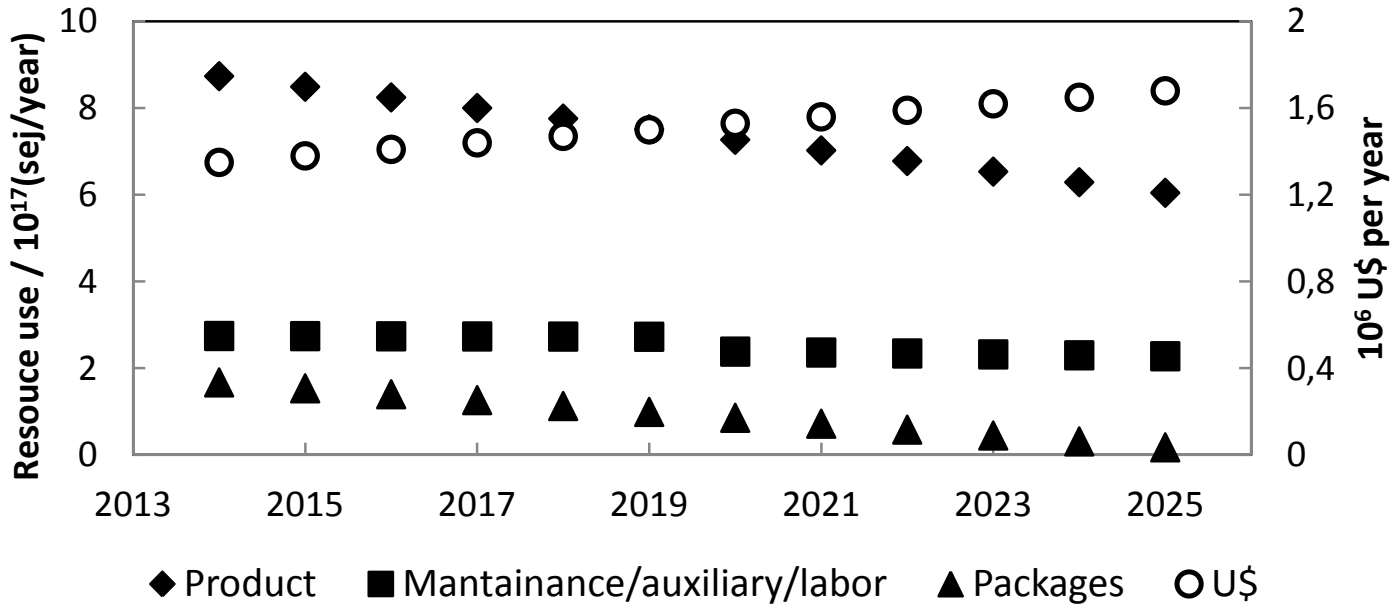

Figure 2. Emergy into products, maintenance, auxiliary materials, labor and packaging materials from 2014 to 2025.

In regard to the emergy costs represented into currency values, results shown in Figure 3 make clear that the product change will benefit not only the company, reducing the environmental costs by $35 \%$, but also that the global productivity will increase by $55 \%$, due to the lesser use of raw, auxiliary and packaging materials and energy savings. 


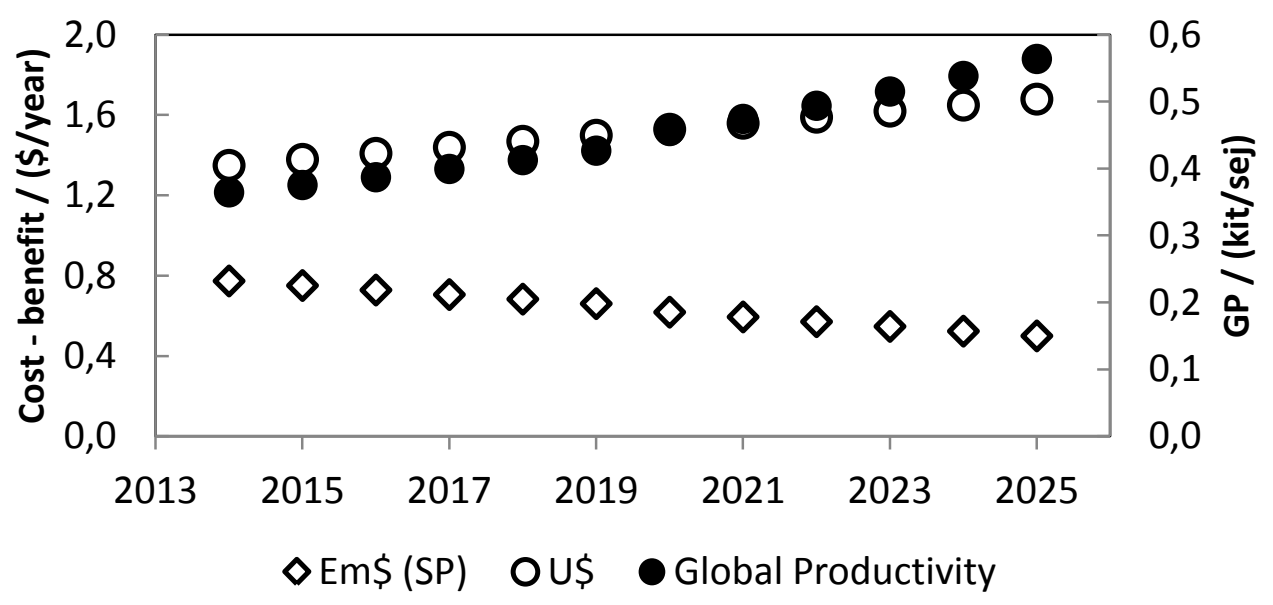

Figure 3. Cost/Benefit and Global Productivity of JP JUNTAS from 2014 to 2025.

All results show that a technological change that occurred elsewhere in the supply chain can have beneficial effects on small businesses that exist and survive around the main chain. The gains due to increased global productivity benefit not only entrepreneurs and small business owners, but also the environment, since part of saved resources and energy can be used for other purposes (Fig. 4). The Emergy/Revenue relationship, which decreases by $48 \%$, shows that the product change of makes the company more eco-efficient, as it profits more with less use of resources and energy.

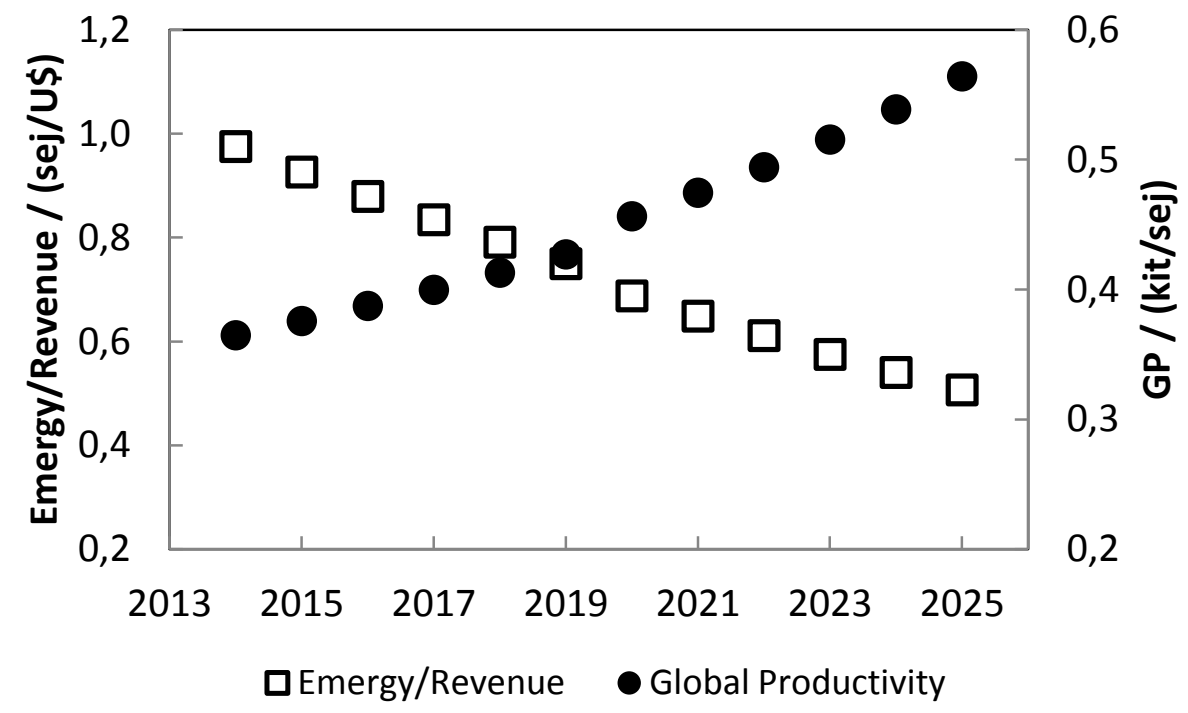

Figure 4. Figure 3. Emergy/Revenue and Global Productivity of JP JUNTAS from 2014 to 2025.

\section{Conclusions}

The assessment of a small company in the Brazilian automotive aftermarket confirms the idea that the supply chain thinking works to reduce the environmental the burden associated with products manufacturing within the value chain. Results show that product change in the small company induced by a technological change in the main supply chain can lead to environmental and economic benefits. Social benefits, which seem disadvantaged due to cutting of manpower for 2010, may be compensated if they are reassessed in the light of the implementation of a staff training program, which may increase the possibility of these workers to get better jobs or perform duties of greater responsibility in the company. The simulation results for the period 2014-2025, within the company's business plan, shows that the sooner the exchange of products is made, the greater the profits of the company with regard to ecoefficiency and environmental responsibility. 


\section{References}

1- Odum, H.T.,Environmental Accounting: Emergy and Environmental Decision Making. John Wiley \& Sons, New York p. 370 (1996)

2- K. Cao and X. Feng The Emergy Analysis of Multi-Product Systems Trans IChemE, Part B, Process Safety and Environmental Protection, 85 (B5): 494-500 (2007).

3- Yong Geng a, Pan Zhang b,1, Sergio Ulgiati c,2, Joseph Sarkis d,3 Emergy analysis of an industrial park: The case of Dalian, China Science of the Total Environment 408, 5273-5283 (2010)

4- Hanfeng Mua, Xiao Fengb, Khim Hoong Chua Improved emergy indices for the evaluation of industrial systems incorporating waste management Ecological Engineering 37, 335-342 (2011)

5- B.F. Giannetti, S.H. Bonilla, I.R. Silva, C.M.V.B. Almeida Cleaner production practices in a medium size gold-plated jewelry company in Brazil: when little changes make the difference Journal of Cleaner Production 16,1106 e1117 (2008)

6- C.M.V.B. Almeida, M.A. Madureira, S.H. Bonilla, B.F. Giannetti Assessing the replacement of lead in solders: effects on resource use and human health Journal of Cleaner Production, Volume 47, Pages 457-464, May (2013)

7- Odum, H.T.,Odum,E.P.:The energetic basis for valuing eco system services,(2000).Ecosystems 3(1),21-23.Demétrio, (2007)

8- Campbell, E.T., Tilley, D.R.:The eco-price: How environmental emergy equates to currency. (2014) .Ecosystem Services, http://dx.doi.org/10.1016/j.ecoser.2013.12.002i (2014)

9- Demétrio, J.F.C. Emergy Environmental Sustainability Assessment of Brazil, Ph. D. dissertation. Universidade Paulista,São Paulo, Brazil (in Portuguese), (2011).

〈http://www3.unip.br/ensino/pos_graduacao/strictosensu/lab_producao_meio ambiente/realizacoes_academicas.aspx\#ra4, last accessed in July (2013). 